\title{
Worker Injuries Involving the Interaction of Cattle, Cattle Handlers, and Farm Structures or Equipment
}

\author{
S. Fox, M. Ricketts, J. E. Minton
}

\begin{abstract}
Cattle have been identified as leading sources of injuries to agricultural workers. The present study focused on worker injuries that involved the interaction of cattle, cattle handlers, and farm structures or equipment. The goal of the study was to identify opportunities for injury prevention. We examined 221 reports of injury to cattle handlers from the Consumer Product Safety Commission's National Electronic Injury Surveillance System (NEISS). Expected interactions led to many of the cattle-handling injuries reported in the NEISS database. In almost $30 \%$ of cases, cattle pushed workers into structures such as fences, gates, posts, and walls. In another $16 \%$ to $19 \%$ of injuries, cattle struck gates and other objects, propelling them at the victims. The present research makes several important contributions to the study of cattle-handling injuries. First, the research supports an increased emphasis on the development of safer gate designs (e.g., gates that are remotely operated or that absorb energy to limit the speed at which they may be propelled by animals). Second, the research suggests a need for additional study of energy-absorbing fence and wall structures. We view these two points to be of significance because gates and associated structures (e.g., posts, fences, and walls) accounted for $45 \%$ of the injuries in the dataset, based on the associated injury narrative. Finally, the research identifies a previously unexplored source of agricultural injury data, namely the NEISS database.
\end{abstract}

Keywords. Agricultural accidents, Agricultural injuries, Cattle, Cattle handling, Farm accidents, Farm injuries, Injuries, Safety.

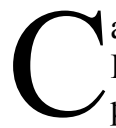

attle and other livestock are leading sources of injuries to workers in agriculture. Livestock handling activities accounted for about one-fourth of all workers' compensation claims in Colorado dairies and facilities where beef cattle were produced and sold (Douphrate et al., 2006, 2009). Not only were livestock-handling injuries common in these settings, they also tended to be severe, typically involving more serious diagnoses and greater costs per claim compared with other types of injuries.

Cattle accounted for a large proportion of all documented animal-handling injuries (Douphrate et al., 2006, 2009; Langley and Hunter, 2001; Layde et al., 1996; Norwood et al., 2000). In fact, an analysis of data from the Bureau of Labor Statistics indicated that

Submitted for review in April 2013 as manuscript number JASH 10221; approved for publication by the Ergonomics, Safety, \& Health Community of ASABE in September 2014.

The authors are Shannon Fox, Administrative Assistant to the Dean, Graduate School, Kansas State University, Manhattan, Kansas; Mitch Ricketts, Assistant Professor, Department of Information Systems and Technology, Northeastern State University, Broken Arrow, Oklahoma; J. Ernest Minton, Associate Director, Agricultural Experiment Station, Kansas State University, Manhattan, Kansas. Corresponding author: Mitch Ricketts, 124C Business and Technology, Northeastern State University, Broken Arrow, OK 74014; phone: 918-449-6500; e-mail: ricketts@nsuok.edu.

Journal of Agricultural Safety and Health 
cattle were responsible "for more fatal work injuries than any other animal" in the U.S. (Drudi, 2000, p. 18). The circumstances of cattle-related injuries are being more closely evaluated by researchers, and some findings may have important implications for prevention. For instance, Douphrate et al. $(2006,2009)$ found that cattle-handling injuries in Colorado often occurred when dairy workers were either kicked or stepped on while milking. Similarly, Casey et al. (1997b) found that dairy workers in New York State were frequently injured while washing udders or attaching milking equipment. These findings raise the possibility that injuries might be prevented through the redesign of milking equipment and procedures. In fact, Douphrate et al. (2009) recommended that "injury prevention efforts should be directed at livestock-handling facility and equipment design" (pp. 404-405), and Casey et al. (1997a, 1997b) stated that improved facilities and work practices could prevent many injuries.

In beef and dairy settings overall, injuries have been especially common where workers and cattle are crowded together in barns, alleys, and pens (Casey et al., 1997a, 1997b; Douphrate et al., 2006, 2009; Grandin, 1997). This realization has led to calls for improved physical barriers and new work procedures designed to keep cattle calm and separated from their handlers (Grandin, 1997; NCR-197, 2003).

Although physical barriers appear to be important, it is not always clear how those barriers should be designed. In fact, recent research has suggested that some farmstead barriers may actually contribute to serious injuries among cattle handlers. For instance, many workers have been crushed by cattle against rigid, stationary structures such as fences, posts, barn walls, stalls, chutes, stanchions, and barn doors (Austin, 1998; Casey et al., 1997b; Douphrate et al., 2009; Hoskin and Miller, 1979; Lindsay et al., 2004; Mainzer, 1966; Rautiainen et al., 2004; Waller, 1992). In other cases, workers have been struck by steel gates or doors that were swung open with great force after being hit by cattle (CDC, 2009; Day, 1996; Douphrate et al., 2009; Hendricks and Adekoya, 2001; Sheldon et al., 2009).

The present study focused on worker injuries that involved the interaction of three elements: (1) cattle, (2) cattle handlers, and (3) farm structures or equipment, including swinging gates and stationary barriers. The goal of the study was to identify the most frequent circumstances that led to the injury. The source of injury cases was the Consumer Product Safety Commission (CPSC) National Electronic Injury Surveillance System (NEISS) (CPSC, 2009). This source of data was chosen because it includes product codes for many farmstead barriers such as fences, walls, and doors. We believe this is the first analysis based upon the NEISS narratives that provides insight into the circumstances of each cattle-related incident.

\section{Material and Methods}

The CPSC NEISS maintains data on patients from a sample of 100 hospitals throughout the U.S. The hospitals represent a probability sample of all U.S. emergency rooms. Each hospital collects patient information from emergency room visits that involve consumer products. For every visit, the data collected include a short narrative describing the injury and coded data such as date, gender, age, diagnosis, and body part injured.

For the years 2002-2009, we searched all cases in the NEISS database for the following keywords: calf, calves, bull, steer, heifer, cow, and cattle. This search resulted in 7,686 injury reports. The 7,686 reports were then independently reviewed by two investi- 
gators to eliminate reports that were clearly not related to cattle handling (e.g., a child was struck in the calf by a toy, a victim was struck in the leg by a bullet, a man in a car crash struck his chest against the steering wheel, and a woman was kicked by someone wearing cowboy boots). We also excluded sporting injuries such as bull riding and vehicular accidents in which victims were clearly not handling cattle in an agricultural setting (e.g., a car rounded a curve in the highway and struck a cow that was standing in the road). After review, there were 221 reports involving injuries associated with cattle handling $(98.64 \%$ initial agreement between investigators; all discrepancies were easily resolved through discussion).

Based on events described in the narratives of the NEISS injury reports, ten mutually exclusive injury scenarios were developed to characterize the 221 cattle-handling injuries (table 1). Our approach was similar to and patterned on an earlier report of narratives used to characterize injuries of U.S. Army truck drivers (Lincoln et al., 2004). Two investigators independently assigned each of the 221 reports to the ten injury scenarios (99.10\% initial agreement; all discrepancies were easily resolved). Each of the 221 reports was also designated as "definitely" or "probably" belonging to the assigned injury scenario (95.48\% initial agreement; all discrepancies were easily resolved). Table 1 provides representative examples of narratives for the ten injury scenarios.

Table 1. Injury scenarios used to categorize cattle injury circumstances based on narratives in the National Electronic Injury Surveillance System (NEISS) database for calendar years 2002-2009. ${ }^{[a]}$

\begin{tabular}{|c|c|c|c|}
\hline Scenario & Example & $N$ & $\begin{array}{c}\% \text { of Total } \\
\text { Injuries }\end{array}$ \\
\hline $\begin{array}{c}\text { Animal strike } \\
\text { Definite }\end{array}$ & $\begin{array}{l}\text { s human, human strikes farmstead structure (e.g., fence, gate, post, wall) } \\
\text { Case 20532477: RT RIB PAIN X } 1 \text { WK. HIT BY COW, THROWN INTO } \\
\text { GATE. DX; RT RIB CONT. }\end{array}$ & $\begin{array}{l}63 \\
63\end{array}$ & $\begin{array}{l}28.51 \\
28.51\end{array}$ \\
\hline $\begin{array}{c}\text { Cattle handlin } \\
\text { Definite }\end{array}$ & $\begin{array}{l}\text { ag, but contact with animal not explicitly mentioned } \\
\text { Case } 81127299: \text { PT FEEDING CATTLE AND FELL OFF FENCE - NOT } \\
\text { USING ARM, OCCURRED SEVERAL HOURS EARLIER. CONTUSION } \\
\text { ELBOW. }\end{array}$ & $\begin{array}{l}45 \\
17\end{array}$ & $\begin{array}{c}20.36 \\
7.69\end{array}$ \\
\hline Probable & $\begin{array}{l}\text { CPSC Case 90308918: FELL ON METAL COW FEEDER; DX CON- } \\
\text { TUSED KIDNEY AND SPLEEN; DX CONTUSED UPPER TRUNK. } \\
\text { [Authors' note: Probable (not definite) that victim was handling cattle.] }\end{array}$ & 28 & 12.67 \\
\hline $\begin{array}{c}\text { Animal strike } \\
\text { Definite }\end{array}$ & $\begin{array}{l}\text { s farmstead structure (e.g., fence, gate, post, wall), object strikes human } \\
\text { CPSC CaSe 90207125: COW PUSHED GATE OPEN AND GATE HIT } \\
\text { FACE, HAS CONCUSSION, LACERATION TO FOREHEAD. }\end{array}$ & $\begin{array}{l}41 \\
35\end{array}$ & $\begin{array}{l}18.55 \\
15.84\end{array}$ \\
\hline Probable & $\begin{array}{l}\text { CPSC Case 30935178: PT WAS WORKING WITH CATTLE AND MET- } \\
\text { AL GATE HIT PT IN HEAD CAUSING LOSS OF CONSCIOUSNESS } \\
\text { FOR UNKNOWN AMT OF TIME; HEAD CONTUSION, FX RT FACE. } \\
\text { [Authors' note: Probable (not definite) that cattle hit gate.] }\end{array}$ & 6 & 2.71 \\
\hline $\begin{array}{c}\text { Tangled in ro } \\
\text { Definite }\end{array}$ & & $\begin{array}{l}18 \\
17\end{array}$ & $\begin{array}{l}8.14 \\
7.69\end{array}$ \\
\hline Probable & $\begin{array}{l}\text { CPSC Case 50849536: PATIENT WAS RIDING HIS HORSE, ROPING A } \\
\text { CALF, GOT FINGER IN THE ROPE AND AMPUTATED IT. DX; AM- } \\
\text { PUTATED L RING FINGER. } \\
\text { CPSC Case 40834278: ROPING CATTLE DX FINGER FX, DISLOCA- } \\
\text { TION AND AVULSION. [Authors' note: Probable (not definite) that rope } \\
\text { caused injury.] }\end{array}$ & 1 & 0.45 \\
\hline
\end{tabular}


Table 1 (continued). Injury scenarios used to categorize cattle injury circumstances based on narratives in the National Electronic Injury Surveillance System (NEISS) database for calendar years 2002-2009. ${ }^{\text {a }}$

\begin{tabular}{|c|c|c|c|}
\hline Scenario & Example & $N$ & $\begin{array}{c}\% \text { of Total } \\
\text { Injuries }\end{array}$ \\
\hline \multicolumn{2}{|c|}{ Animal strikes human, no farmstead structures involved } & 15 & 6.79 \\
\hline \multirow[t]{2}{*}{ Definite } & & 10 & 4.52 \\
\hline & $\begin{array}{l}\text { CPSC Case } 71001562: \text { CHI. PT WAS KICKED IN HEAD BY A COW } \\
\text { AND FELL TO CEMENT FLOOR. }\end{array}$ & & \\
\hline \multirow[t]{2}{*}{ Probable } & & 5 & 2.26 \\
\hline & $\begin{array}{l}\text { CPSC Case 70533306: KNOCKED DOWN BY COW COMING } \\
\text { THROUGH GATE. LT SHOULDER STRAIN. [Authors' note: Probable } \\
\text { (not definite) that no structures were involved.] }\end{array}$ & & \\
\hline \multicolumn{4}{|c|}{ Incident involving horse or ATV } \\
\hline \multicolumn{2}{|c|}{ Contact by animal not explicitly mentioned } & 14 & 6.33 \\
\hline \multirow[t]{2}{*}{ Definite } & & 11 & 4.98 \\
\hline & $\begin{array}{l}\text { CPSC Case 20644500: PATIENT HURT WHEN } 4 \text { WHEELER TURNED } \\
\text { OVER WHILE PULLING A BULL. (DOESN'T STATE IF JOB RELAT- } \\
\text { ED). DX: LEFT RIB (UPPER CHEST) CONTUSION. }\end{array}$ & & \\
\hline \multirow[t]{2}{*}{ Probable } & & 3 & 1.36 \\
\hline & $\begin{array}{l}\text { CPSC Case 20606614: WENT OFF EMBANKMENT WHILE ROUND- } \\
\text { ING UP CATTLE. NONWORK LACERATION TO FOREHEAD. [Au- } \\
\text { thors' note: Probable (not definite) no animal contact occurred.] }\end{array}$ & & \\
\hline \multirow{5}{*}{$\begin{array}{c}\text { Contact be } \\
\text { Definite }\end{array}$} & veen animal and horse/ATV & 8 & 3.62 \\
\hline & & 8 & 3.62 \\
\hline & CPSC Case 31103440: RIDING HORSE WORKING COWS AT HOME, & & \\
\hline & COW RAN INTO HORSE KNOCKING DOWN HORSE AND RIDER & & \\
\hline & INJURING RIBS. DX: FRACTURE RIBS. & & \\
\hline \multirow{4}{*}{$\begin{array}{r}\text { Hurt while } t \\
\text { Definite }\end{array}$} & ing to escape from animal & 9 & 4.07 \\
\hline & & 9 & 4.07 \\
\hline & CPSC Case 31009446: 56 Y/O WHITE MALE FRACTURED HIP WHEN & & \\
\hline & FELL OFF FENCE TRYING TO GET AWAY FROM COW AT HOME. & & \\
\hline \multirow{4}{*}{$\begin{array}{c}\text { Cut/punctur } \\
\text { Definite }\end{array}$} & d while butchering animal & 6 & 2.71 \\
\hline & & 6 & 2.71 \\
\hline & CPSC Case 30423022: LACERATION HAND. PATIENT REPORTS HE & & \\
\hline & CUT HIS RT HAND WITH A KNIFE WHILE BUTCHERING A COW. & & \\
\hline \multirow{4}{*}{$\begin{array}{c}\text { Cut/punctur } \\
\text { Definite }\end{array}$} & d while performing animal care & 2 & 0.90 \\
\hline & & 2 & 0.90 \\
\hline & CPSC Case 20511679: WAS CASTRATING A BULL WHEN GOT & & \\
\hline & $\begin{array}{l}\text { KICKED WHILE HOLDING A KNIFE. LACERATION AT DORSUM LT } \\
\text { HAND } 2 \text { CM. }\end{array}$ & & \\
\hline Total & & 221 & 100.00 \\
\hline
\end{tabular}

[a] "Cattle" refers to cow, calf, calves, bull, steer, heifer, or cattle.

In addition to descriptive statistics, we employed chi-square tests to identify injury patterns. For chi-square tests involving injury diagnoses, expected frequencies were calculated by applying the proportion of each diagnosis from non-cattle-related NEISS cases to the 221 cases involving cattle. For instance, among the 2,920,574 non-cattle-related cases during the years of study, $17.27 \%$ of diagnoses consisted of strains and sprains. The 38 expected cattle-related strains and sprains represent $17.27 \%$ of the 221 total cattlehandling injuries. Expected frequencies for chi-square tests involving injured body parts were calculated in the same manner.

The research was reviewed and approved by the Institutional Review Board of Kansas State University. All data were drawn from a publicly available database on the internet. The database contained no personally identifiable information about participants; therefore, written consent of participants was not obtained. 


\section{Results}

Cattle-handling injuries accounted for $221(0.0076 \%)$ of the 2,920,795 cases in the NEISS database during 2002-2009. Female workers accounted for $20 \%$ of cattle-handling injuries. The ages of victims in cattle-handling incidents ranged from 1 to 88 years $($ mean $=40, \mathrm{SD}=22)$ (fig. 1). Children between the ages of 1 and 17 accounted for $19 \%$ of the injuries (fig. 1). Cows and heifers were involved in $125(56 \%)$ of the cattle-related injuries, while bulls or steers were involved in $39(18 \%)$. Animal gender was not reported in 57 cases $(26 \%)$.

\section{Circumstances Surrounding Injuries}

The consumer product involved in 124 (56\%) of all cattle-related injuries was fences or fence posts (including gates). In 19 (9\%) of cases, rope or string products were involved, 16 (7\%) involved horseback riding (activity, apparel, or equipment), 11 (5\%) involved allterrain vehicles (four-wheel offroad only), 9 (4\%) involved ceilings and walls (part of a completed structure), and 8 (4\%) involved knives (not elsewhere classified).

Over one-fourth of all cattle-handling injuries occurred when cattle struck a victim, causing the victim to then strike a farmstead structure (e.g., fence, gate, post, or wall). Investigators reported that all 63 of these incidents definitely fit the scenario, indicating that the facts were clear in the NEISS narratives (table 1).

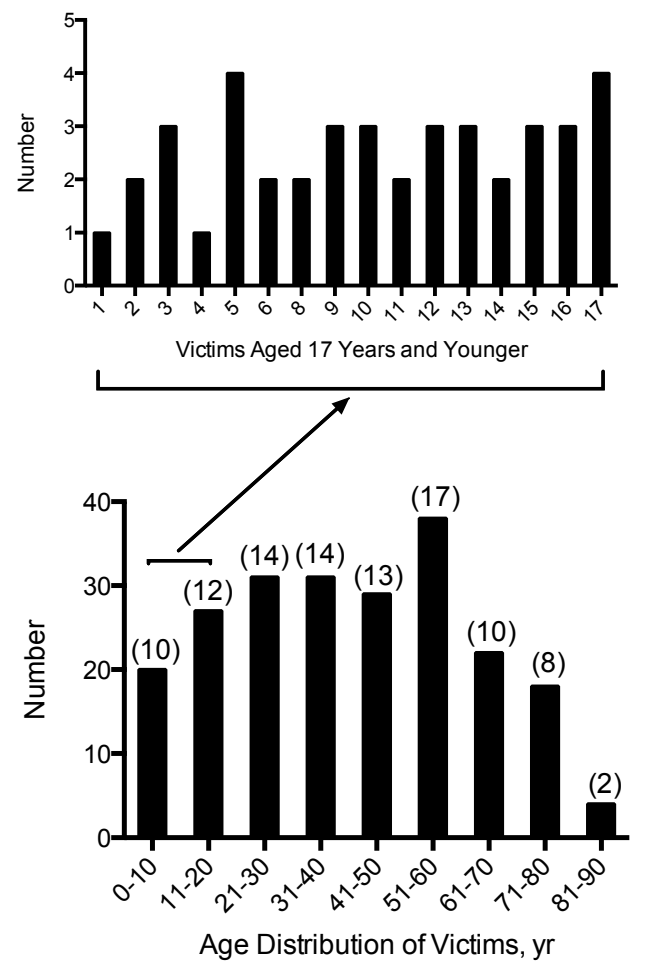

Figure 1. Age distribution of injury victims as reported in the National Electronic Injury Surveillance System (NEISS) database for calendar years 2002-2009. Numbers above bars are percentages of the total that each bar represents. Inset (top) shows detailed distribution of victims age 17 and younger. 
In one-fifth of cattle-handling injuries, contact with an animal was not explicitly mentioned in the NEISS reports (table 1). The narratives for these incidents were not always clear; consequently, the investigators determined that only 17 of the 45 cases definitely fit the scenario, mainly due to uncertainty about whether victims were handling cattle at the time of injury.

Slightly less than one-fifth of cattle-handling injuries occurred when cattle struck farmstead structures (primarily gates), and the farmstead structures then struck the human victims. Reports of these cases were relatively straightforward: 35 definitely fit the scenario, and 6 were probable.

Other scenarios accounted for fewer incidents. For instance, about $8 \%$ of the cattlehandling injuries occurred when victims became entangled in rope (17 definite, 1 probable). About $7 \%$ of the incidents occurred when cattle struck victims and no impact with farmstead structures occurred (10 definite, 5 probable, indicating uncertainty about whether all incidents occurred while handling cattle). About $6 \%$ of the cases involved horses or all-terrain vehicles (ATVs) but contact by cattle was not explicitly mentioned (11 definite, 3 probable). Incidents involving horses or ATVs that explicitly mentioned contact with cattle accounted for about $4 \%$ of cattle-handling injuries ( 8 definite, 0 probable). About $4 \%$ of the incidents occurred when victims were trying to escape from cattle ( 9 definite, 0 probable). Other incidents involved cuts and punctures suffered while harvesting cattle for beef $(2.71 \%, 6$ definite, 0 probable) and while performing animal care $(0.90 \%, 2$ definite, 0 probable $)$.

\section{Treatments Received for Injuries}

NEISS codes for injury disposition indicate the extent of treatment offered by healthcare providers and accepted by patients. Among the 221 cattle-handling incidents, 195 victims $(88 \%)$ were treated and released and one victim $(<1 \%)$ left without treatment. The remaining 25 victims (11\%) were treated and received further medical attention, 16 (7\%) were admitted to the presenting hospital, eight (4\%) were treated and transferred to another hospital, and one ( $<1 \%$ ) was held for observation).

\section{Body Parts Injured}

The NEISS coding manual includes 26 mutually exclusive categories that indicate which part of the body was most seriously injured in each incident. Of those 26 body parts, just seven accounted for the main site of injury in $68 \%$ of all cattle-related cases: the fingers, face, head, upper trunk, hand, lower trunk, and shoulder (fig. 2). In contrast, these seven body parts accounted for just $55 \%$ of all non-cattle-related cases in the NEISS database for the years of study. The distribution of injuries among these seven body parts was not significantly different between cattle-related and non-cattle-related incidents in the NEISS database $\left(\chi^{2}(6)=9.84, \mathrm{p}=0.135\right)$.

\section{Nature of Injuries}

The NEISS coding manual includes 30 mutually exclusive diagnoses; however, just four of those diagnoses accounted for $75 \%$ of all cattle-related injuries: lacerations, contusions/abrasions, fractures, and strains/sprains (fig. 3). The overall distribution of injuries among these four diagnoses differed between the cattle-related injuries and the noncattle-related incidents in the NEISS database $\left(\chi^{2}(3)=11.52, \mathrm{p}=0.009\right)$. 


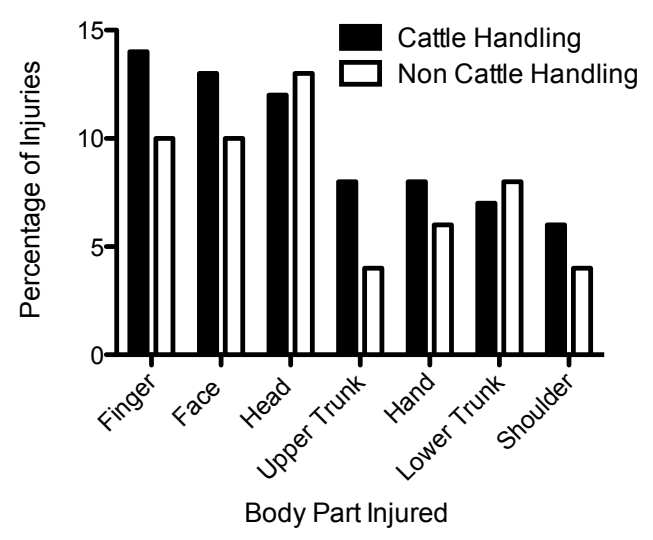

Figure 2. Percentages of injuries to specific body parts that were or were not associated with cattle handling as reported in the National Electronic Injury Surveillance System (NEISS) database for calendar years 2002-2009. The distribution of injuries among these seven body parts was not significantly different between cattle-related and non-cattle-related incidents in the NEISS database $\left(\chi^{2}(6)=9.84, p=0.135\right)$.

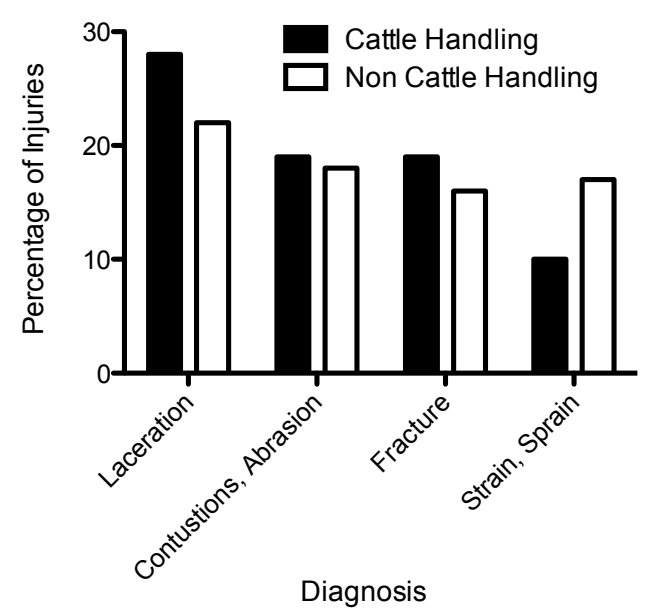

Figure 3. Percentages of injury diagnoses that were or were not associated with cattle handling as reported in the National Electronic Injury Surveillance System (NEISS) database for calendar years 2002-2009. The overall distribution of injuries among these four diagnoses differed between cattle-related and noncattle-related incidents in the NEISS database $\left(\chi^{2}(3)=11.52, p=0.009\right)$.

\section{Discussion}

The current study suggests that many cattle-handling injuries are related to expected interactions between humans, animals, and farm structures. These findings are consistent with reports calling for safety-related modifications to equipment (e.g., gates) and hazardous work practices (e.g., workers present with cattle in crowded pens).

We found that almost $30 \%$ of injuries occurred when workers were pushed into structures such as fences, gates, posts, and walls. An additional 16\% to $19 \%$ of injuries occurred when cattle struck gates or other objects, propelling them at victims. These percentages are consistent with findings reported in previous studies that drew on data 
from New York hospitals (Casey et al., 1997b), news reports in the central U.S. (CDC, 2009), and workers compensation cases in Colorado (Douphrate et al., 2006, 2009). In all, gates and other physical barriers were involved in about $45 \%$ of cattle-handling injuries in the present study.

The NEISS data also confirmed that injuries are common while working with cattle in enclosed areas, moving or herding cattle, loading, and feeding (Casey et al., 1997b; Mainzer, 1966; Rautiainen et al., 2004; Sheldon et al., 2009). Taken together, the findings of the present study support the calls of previous researchers for increased efforts toward the design and adoption of safer farm structures, equipment, and work practices.

Considerable progress has been made in the design of facilities that keep cattle calm and separated from humans (Bentley et al., 2005; Grandin, 1997; Stafford, 2005). However, the expense of these design enhancements may prevent their adoption on family farms and in other low-volume cattle-handling operations. It seems likely that some direct contact between cattle and caretakers will always be required. It may be necessary, therefore, to explore additional options, such as structures that absorb some of the impact when workers are forced against structures by an animal. In fact, this approach was proposed more than two decades ago by Waller (1992).

Some progress toward the development of safer gate designs has been recommended. For instance, Bentley et al. (2005) and Stafford (2005) recommended the use of revolving oneway gates that pivot $360^{\circ}$ on a center post. These gates incorporate ratchet mechanisms to prevent cattle from pushing them back toward workers. The same authors recommended features that eliminate the need for workers to approach when cattle are nearby. Examples of these features include remote-opening (e.g., cord-operated) latches, self-closing latches, and gates that swing shut on their own. These authors further discussed sliding gates and other non-swinging designs as alternatives, emphasizing the importance of keeping gates properly maintained so they always operate as intended with humans safely outside the danger zone.

Our research also confirmed that animal-related injuries often include bruises, contusions, strains, sprains, fractures, and abrasions, while affected body parts typically include the face, chest, lower arm, wrist, hand, fingers, ankle, foot, and toes (Douphrate et al., 2006, 2009; Layde et al., 1996).

We noted injuries across all age ranges and both genders of workers, similar to the findings of previous studies (Douphrate et al., 2006, 2009; Langley and Hunter, 2001; Murphy et al., 2010). Recently, there has been increased interest in injuries to youth in agriculture, including proposed revisions to child labor regulations in the U.S. (DOL, 2011). Because of serious limitations in the data for farm workers, it is difficult to calculate meaningful injury rates for youth in animal production; however, figure 1 illustrates that some cattle-related injuries among youth were recorded in NEISS. As with the NEISS-reported injuries among adults, it is not possible to determine how many of the incidents occurred in the course of paid employment.

As a potential limiting factor, it is important to note that this is an analysis of an existing data set with a small sample size. The data were confined to injuries captured by the NEISS reporting system of the U.S. Consumer Product Safety Commission. To be included in the NEISS data, the injury had to be reported not only to hospitals that contributed to the data set, but also had to include a consumer product. However, the similarity of our findings to those of other researchers suggests that the results were representative of cattle-handling injuries identified using other data collection systems. 


\section{Conclusion}

The present research makes several important contributions to the study of cattlehandling injuries. First, the research supports greater emphasis on the development of safer gate designs (e.g., gates that are remotely operated or that absorb energy to limit the speed at which they may be propelled by animals). Second, the research points to a need for additional study of energy-absorbing fence and wall structures. We view these two points to be of significance because gates and associated structures (e.g., posts, fences, and walls) accounted for $45 \%$ of the injuries in the dataset, based on the associated injury narrative. Finally, the research identifies a previously unexplored source of agricultural injury data, namely the NEISS database.

\section{References}

Austin, C. C. (1998). Nonvenomous animal-related fatalities in the United States workplace, 19921994. J. Agromed., 5(1), 5-15. http://dx.doi.org/10.1300/J096v05n01_02.

Bentley, T., Tappin, D., Moore, D., Legg, S., Ashby, L., \& Parker, R. (2005). Investigating slips, trips, and falls in the New Zealand dairy farming sector. Ergonomics, 48(8), 1008-1019. http://dx.doi.org/10.1080/00140130500182072.

Casey, G. M., Grant, A. M., Roerig, D. S., Boyd, J., Hill, M., London, M., Gelberg, K. H., Hallman, E., \& Pollock, J. (1997a). Farm worker injuries associated with bulls: New York State 1991-1996. AAOHN J., 45(8), 393-396.

Casey, G. M., Grant, A. M., Roerig, D. S., Boyd, J., Hill, M., London, M., Gelberg, K. H., Hallman, E., \& Pollock, J. (1997b). Farm worker injuries associated with cows: New York state 1991-1996. AAOHN J., 45(9), 446-450.

CDC. (2009). Fatalities caused by cattle-four states, 2003-2008. MMWR, 58(29), 800-804.

CPSC. (2009). National Electronic Injury Surveillance System (NEISS). Bethesda, Md.: U.S. Consumer Product Safety Commission. Retrieved from www.cpsc.gov/library/neiss.html.

Day, L. M. (1996). Dairy farm injury in Victoria. Report No. 96. Clayton, Victoria, Australia: Monash University Accident Research Centre. Retrieved from www.monash.edu.au/muarc/reports/muarc096.pdf.

DOL. (2011). Child labor regulations, orders and statements of interpretation; child labor violations-civil money penalties. Washington, D.C.: U.S. Department of Labor. Retrieved from www.gpo.gov/fdsys/pkg/FR-2011-09-02/pdf/FR-2011-09-02.pdf.

Douphrate, D. I., Rosecrance, J. C., \& Wahl, G. (2006). Workers' compensation experience of Colorado agriculture workers, 2000-2004. American J. Ind. Med., 49(11), 900-910. http://dx.doi.org/10.1002/ajim.20387.

Douphrate, D. I., Rosecrance, J. C., Stallones, L., Reynolds, S. J., \& Gilkey, D. P. (2009). Livestockhandling injuries in agriculture: An analysis of Colorado workers' compensation data. American J. Ind. Med., 52(5), 391-407. http://dx.doi.org/10.1002/ajim.20686.

Drudi, D. (2000). Are animals occupational hazards? In Compensation and Working Conditions (Fall 2000), 15-22. Washington, D.C.: Bureau of Labor Statistics.

Grandin, T. (1997). The design and construction of facilities for handling cattle. Livestock Prod. Sci., 49(2), 103-119. http://dx.doi.org/10.1016/S0301-6226(97)00008-0.

Hendricks, K., \& Adekoya, N. (2001). Non-fatal animal-related injuries to youth occurring on farms in the United States, 1998. Injury Prev., 7(4), 307-311. http://dx.doi.org/10.1136/ip.7.4.307.

Hoskin, A. F., \& Miller, T. A. (1979). Farm accident surveys: A twenty-one state summary with emphasis on animal-related injuries. J. Safety Res., 11(1), 2-13.

Langley, R. L., \& Hunter, J. L. (2001). Occupational fatalities due to animal-related events. Wilderness Environ. Med., 12(3), 168-174. http://dx.doi.org/10.1580/10806032(2001)012[0168:OFDTAR]2.0.CO;2. 
Layde, P. M., Nordstrom, D. L., Stueland, D., Wittman, L. B., Follen, M. A. \& Olson, K. A. (1996). Animal-related occupational injuries in farm residents. J. Agric. Safety Health, 2(1), 27-37. http://dx.doi.org/10.13031/2013.19439.

Lincoln, A., Sorock, G., Courtney, T., Wellman, H., Smith, G., \& Amoroso, P. (2004). Using narrative text and coded data to develop hazard scenarios for occupational injury interventions. Injury Prev., 10(4), 249-254. http://dx.doi.org/10.1136/ip.2004.005181.

Lindsay, S., Selvaraj, S., Macdonald, J. W., \& Godden, D. J. (2004). Injuries to Scottish farmers while tagging and clipping cattle: A cross-sectional survey. Occup. Med. (London), 54(2), 86-91. http://dx.doi.org/10.1093/occmed/kqh032.

Mainzer, W. (1966). Accident prevention in the cowshed. British J. Ind. Med., 23(1), 24-27.

Murphy, C. G., McGuire, C. M., O’Malley, N., \& Harrington, P. (2010). Cow-related trauma: A 10year review of injuries admitted to a single institution. Injury, 41(5), 548-550. http://dx.doi.org/10.1016/j.injury.2009.08.006.

NCR-197. (2003). National agenda for action: National land grant research and extension agenda for agricultural safety and health. NCR-197 Committee on Agricultural Safety and Health Research and Extension. Retrieved from www.nstmop.psu.edu/extension/edc292.pdf.

Norwood, S., McAuley, C., Vallina, V. L., Fernandez, L. G., McLarty, J. W., \& Goodfried, G. (2000). Mechanisms and patterns of injuries related to large animals. J. Trauma, 48(4), 740-744. http://dx.doi.org/10.1097/00005373-200004000-00025.

Rautiainen, R. H., Lange, J. L., Hodne, C. J., Schneiders, S., \& Donham, K. J. (2004). Injuries in the Iowa certified safe farm study. J. Agric. Safety Health, 10(1), 51-63. http://dx.doi.org/10.13031/2013.15674.

Sheldon, K. J., Deboy, G., Field, W. E., \& Albright, J. L. (2009). Bull-related incidents: Their prevalence and nature. J. Agromed., 14(3), 357-369. http://dx.doi.org/10.1080/10599240903042024.

Stafford, K. J. (2005). Cattle Handling Skills. Palmerston North, New Zealand: Massey University, Institute of Veterinary Animal and Biomedical Sciences. Retrieved from www.acc.co.nz/PRD_EXT_CSMP/groups/external_ip/documents/publications_promotion/wim2_ 065192.pdf.

Waller, J. A. (1992). Injuries to farmers and farm families in a dairy state. J. Occup. Med., 34(4), 414421. 